\title{
Cardiovascular Assessment Tool for Breast Cancer Survivors and Oncology Providers: Usability Study
}

Kathryn E Weaver ${ }^{1,2}$, MPH, PhD; Heidi D Klepin ${ }^{3}$, MD; Brian J Wells ${ }^{4,5}$, MD, PhD; Emily V Dressler ${ }^{4}$, PhD; Karen M Winkfield ${ }^{6}, \mathrm{MD}, \mathrm{PhD}$; Zanetta S Lamar ${ }^{3}$, MD; Tiffany P Avery ${ }^{3}, \mathrm{MD}$; Nicholas M Pajewski ${ }^{4}, \mathrm{PhD}$; W Gregory Hundley $^{7}$, MD; Aimee Johnson ${ }^{1}$, PhD; Eleanor C Davidson ${ }^{1}$, BA; Marcelo Lopetegui ${ }^{8}$, MD; Randi E Foraker ${ }^{9}$, MA, $\mathrm{PhD}$

\footnotetext{
${ }^{1}$ Department of Social Sciences and Health Policy, Wake Forest School of Medicine, Winston-Salem, NC, United States

${ }^{2}$ Department of Implementation Science, Wake Forest School of Medicine, Winston-Salem, NC, United States

${ }^{3}$ Section on Hematology-Oncology, Department of Internal Medicine, Wake Forest School of Medicine, Winston-Salem, NC, United States

${ }^{4}$ Department of Biostatistics and Data Science, Wake Forest School of Medicine, Winston-Salem, NC, United States

${ }^{5}$ Department of Family Medicine, Wake Forest School of Medicine, Winston-Salem, NC, United States

${ }^{6}$ Department of Radiation Oncology, Wake Forest School of Medicine, Winston-Salem, NC, United States

${ }^{7}$ Section on Cardiology, Department of Internal Medicine, Wake Forest School of Medicine, Winston-Salem, NC, United States

${ }^{8}$ Instituto de Ciencias e Innovación en Medicina, Facultad de Medicina Clínica Alemana, Universidad del Desarrollo, Santiago, Chile

${ }^{9}$ Institute for Informatics, Washington University in St Louis School of Medicine, St Louis, MO, United States
}

\section{Corresponding Author:}

Randi E Foraker, MA, PhD

Institute for Informatics

Washington University in St Louis School of Medicine

600 S Taylor Avenue, Suite 102

Campus Box 8102

St Louis, MO, 63110

United States

Phone: 13142732211

Email: randi.foraker@wustl.edu

\section{Abstract}

Background: Cardiovascular health is of increasing concern to breast cancer survivors and their health care providers, as many survivors are more likely to die from cardiovascular disease than cancer. Implementing clinical decision support tools to address cardiovascular risk factor awareness in the oncology setting may enhance survivors' attainment or maintenance of cardiovascular health.

Objective: We sought to evaluate survivors' awareness of cardiovascular risk factors and examine the usability of a novel electronic health record enabled cardiovascular health tool from the perspective of both breast cancer survivors and oncology providers.

Methods: Breast cancer survivors $(n=49)$ recruited from a survivorship clinic interacted with the cardiovascular health tool and completed pre and posttool assessments about cardiovascular health knowledge and perceptions of the tool. Oncologists, physician assistants, and nurse practitioners $(\mathrm{n}=20)$ who provide care to survivors also viewed the cardiovascular health tool and completed assessments of perceived usability and acceptability.

Results: Enrolled breast cancer survivors (84\% White race, 4\% Hispanic ethnicity) had been diagnosed 10.8 years ago (SD 6.0) with American Joint Committee on Cancer stage 0, I, or II (45/49, 92\%). Prior to viewing the tool, 65\% of survivors (32/49) reported not knowing their level for one or more cardiovascular health factors (range $0-4$ ). On average, only $45 \%$ (range $0 \%-86 \%$ ) of survivors' known cardiovascular health factors were at an ideal level. More than $50 \%$ of survivors had ideal smoking status $(45 / 48,94 \%)$ or blood glucose level $(29 / 45,64 \%)$; meanwhile, less than 50\% had ideal blood pressure (12/49, 24\%), body mass index $(12 / 49,24 \%)$, cholesterol level $(17 / 35,49 \%)$, diet $(7 / 49,14 \%)$, and physical activity $(10 / 49.20 \%)$. More than $90 \%$ of survivors thought the tool was easy to understand (46/47, 98\%), improved their understanding (43/47, 91\%), and was helpful (45/47, 96\%); overall, 94\% (44/47 survivors) liked the tool. A majority of survivors (44/47, 94\%) thought oncologists should discuss cardiovascular health during survivorship care. Most (12/20, 60\%) oncology providers (female: 12/20, 60\%; physicians: 
$14 / 20,70 \%$ ) had been practicing for more than 5 years. Most providers agreed the tool provided useful information (18/20, $90 \%)$, would help their effectiveness $(18 / 20,90 \%)$, was easy to use $(20 / 20,100 \%)$, and presented information in a useful format (19/20, $95 \%)$; and $85 \%$ of providers (17/20) reported they would use the tool most or all of the time when providing survivorship care.

Conclusions: These usability data demonstrate acceptability of a cardiovascular health clinical decision support tool in oncology practices. Oncology providers and breast cancer survivors would likely value the integration of such apps in survivorship care. By increasing awareness and communication regarding cardiovascular health, electronic health record-enabled tools may improve survivorship care delivery for breast cancer and ultimately patient outcomes.

(JMIR Cancer 2021;7(1):e18396) doi: $\underline{10.2196 / 18396}$

\section{KEYWORDS}

electronic health records; clinical decision support; usability testing; cardiovascular diseases; cancer survivors; breast cancer

\section{Introduction}

Cardiovascular health is of increasing concern to breast cancer survivors and their health care providers [1,2], since older, postmenopausal survivors are more likely to die of cardiovascular disease rather than of cancer $[3,4]$. Breast cancer survivors are at greater risk of death due to cardiovascular disease, compared to age-matched women without a history of breast cancer [5]. Chemotherapy (eg, anthracyclines), monoclonal antibody treatment, hormonal treatments, and radiation all heighten cardiovascular disease risk among survivors [1,6], further increasing cardiovascular disease susceptibility among cancer survivors [5,7,8]. Addressing cardiovascular health is critical for all breast cancer survivors, especially those who receive cardiotoxic treatments $[2,9,10]$.

According to 1582 long-term cancer survivors surveyed in California, $62 \%$ were overweight or obese, $55 \%$ were hypertensive, $21 \%$ were diabetic, $18 \%$ were physically inactive, and 5\% were current smokers [11]. An analysis of these California cancer registry data highlighted the possible role of shared risk factors in the development of both cancer and cardiovascular disease, reporting that cancer survivors tend to have multiple cardiovascular disease risk factors and that survivorship care often does not address these risk factors $[11,12]$. Early recognition and treatment of cardiovascular risk factors may be important during survivorship, as this increased risk of cardiovascular death is evident approximately 7 years postdiagnosis [2,5].

Despite Institute of Medicine recommendations for adequate prevention efforts and care coordination for cancer survivors [13-15], cardiovascular risk continues to be undertreated in this population [16,17]. The majority of National Cancer Institute Community Oncology Research Program oncologists we interviewed (11 of 14) in a pilot study [18] reported cardiovascular health discussions to be "somewhat" or "very" important. Yet in general survivorship settings, few referrals for cardiovascular care are made by oncologists to primary care providers and cardiologists for guideline-driven follow-up care $[11,16,19,20]$.

The American Heart Association's (AHA) definition of cardiovascular health comprises modifiable risk factors, which are scored according to Table 1. Improvements in cardiovascular health can reduce cardiovascular disease and breast cancer recurrence risk [21-26], and increasing patient and provider awareness can enhance cardiovascular health [13]. Most cancer survivors do not meet AHA's healthy standards in multiple cardiovascular health components such as body mass index (BMI), physical activity, diet, smoking, blood pressure, cholesterol level, and glucose level [2,11,21]. 
Table 1. American Heart Association simple 7 measures of cardiovascular health, adapted from [27].

\begin{tabular}{|c|c|c|c|}
\hline Measures & Poor health & Intermediate health & Ideal health \\
\hline \multicolumn{4}{|l|}{ Health behaviors } \\
\hline Smoking status & Current & Former $\leq 12$ months & Never or quit $>12$ months \\
\hline BMI & $\geq 30 \mathrm{~kg} / \mathrm{m}^{2}$ & $25-29.9 \mathrm{~kg} / \mathrm{m}^{2}$ & $<25 \mathrm{~kg} / \mathrm{m}^{2}$ \\
\hline Physical activity & None & $\begin{array}{l}\text { 1-149 minutes/week moderate or } 1- \\
74 \text { minutes/week vigorous or 1-149 } \\
\text { minutes/week moderate and vigorous }\end{array}$ & $\begin{array}{l}\geq 150 \text { minutes/week moderate or } \geq 75 \\
\text { minutes/week vigorous or } \geq 150 \text { min- } \\
\text { utes/week moderate and vigorous }\end{array}$ \\
\hline Healthy diet score & 0-1 components & 2-3 components & 4-5 components \\
\hline \multicolumn{4}{|l|}{ Health factors } \\
\hline Total cholesterol level & $\geq 240 \mathrm{mg} / \mathrm{dL}$ & $200-239 \mathrm{mg} / \mathrm{dL}$ or treated to goal & $<200 \mathrm{mg} / \mathrm{dL}$ \\
\hline Blood pressure & $\begin{array}{l}\text { Systolic } \geq 140 \mathrm{~mm} \mathrm{Hg} \text { or Diastolic } \\
\geq 90 \mathrm{~mm} \mathrm{Hg}\end{array}$ & $\begin{array}{l}\text { Systolic } 120-139 \mathrm{~mm} \mathrm{Hg} \text { or Diastolic } \\
80-89 \mathrm{~mm} \mathrm{Hg} \text { or treated to goal }\end{array}$ & $\begin{array}{l}\text { Systolic }<120 \mathrm{~mm} \mathrm{Hg} \\
\text { Diastolic }<80 \mathrm{~mm} \mathrm{Hg}\end{array}$ \\
\hline \multicolumn{4}{|l|}{ Blood glucose level } \\
\hline $\begin{array}{l}\text { Fasting plasma glu- } \\
\text { cose }\end{array}$ & $\geq 126 \mathrm{mg} / \mathrm{dL}$ & $100-125 \mathrm{mg} / \mathrm{dL}$ or treated to goal & $<100 \mathrm{mg} / \mathrm{dL}$ \\
\hline Hemoglobin $A_{1 c}$ & $\geq 6.5 \%$ & $5.7 \%-6.4 \%$ or treated to goal & $\leq 5.6 \%$ \\
\hline
\end{tabular}

Clinical decision support can provide relevant data to the point-of-care to prompt appropriate disease management and referrals [28]. Our team has previously developed, implemented, and evaluated a cardiovascular health assessment tool, Stroke Prevention in Health care Delivery Environments (SPHERE), in the primary care setting $[29,30]$. Use of SPHERE resulted in improved BMI and diabetes status in the interventional primary care clinic but not the control clinic [31]. We refined this tool based upon feedback received from qualitative interviews with oncologists [18] and added information about receipt of potentially cardiotoxic cancer treatments. For this study, we evaluated the acceptability of the new Automated Heart-Health Assessment tool (AH-HA, Figure 1) among oncology providers and the Vigor-Us mobile app (Figure 1) among breast cancer survivors. We hypothesized that the majority of survivors and oncology providers would express positive views about the tools and their use in the cancer survivorship setting. 
Figure 1. Adapted AH-HA tool (top) and the Vigor-Us tool (bottom).

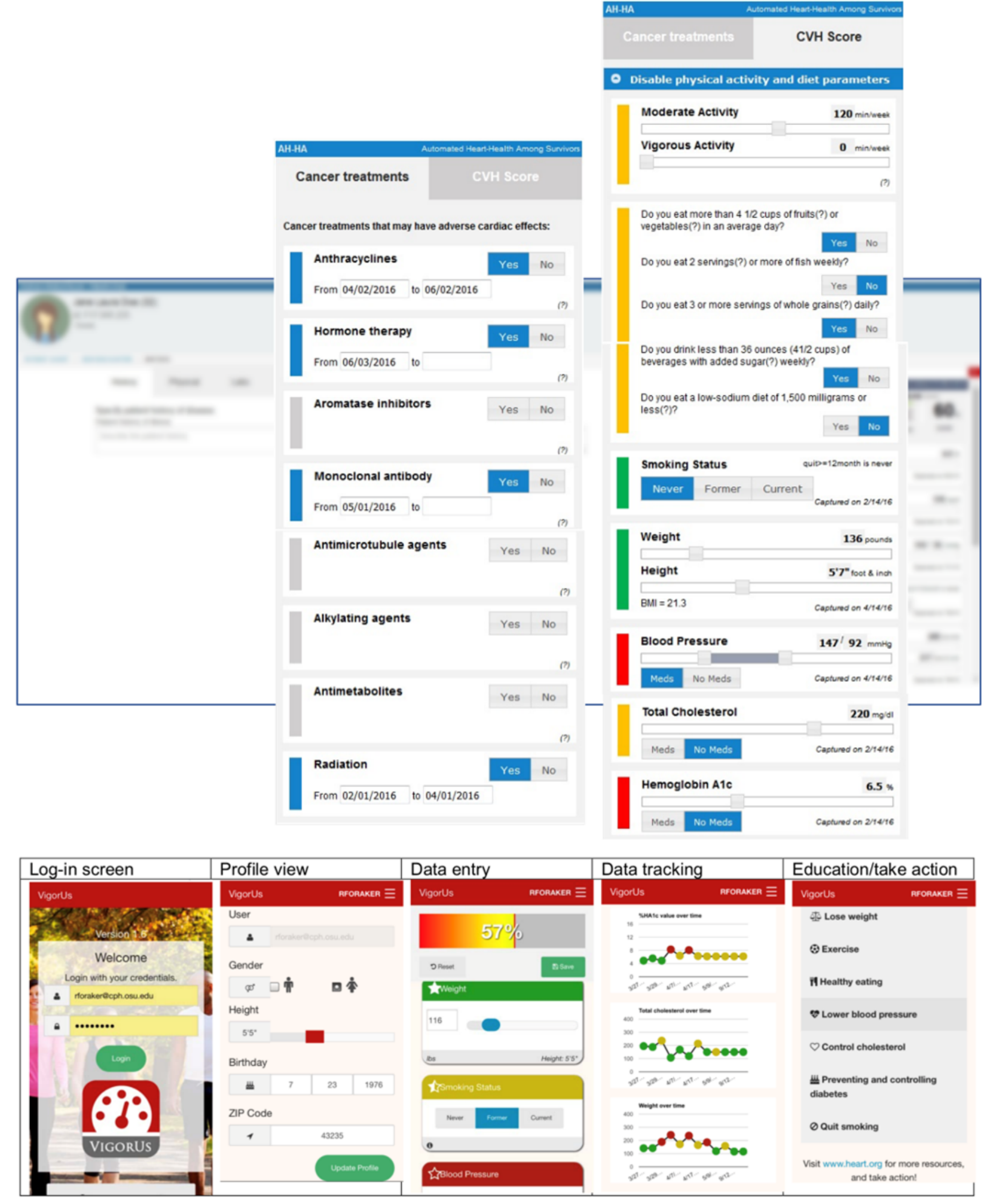

The AH-HA tool was embedded within a simulated electronic health record environment and was intended to be used mainly with a cursor pointer (mouse). The Vigor-Us tool was a responsive web app suitable for both touch and click interactions, with larger interactivity components. AH-HA did not collect any data from the interface, whereas Vigor-Us collected all the information entered during the authenticated sessions (authenticated users, secure sockets layer-encrypted database).

\section{Methods}

\section{Ethical Approval and Informed Consent}

This study was approved by the Wake Forest Health Sciences Institutional Review Board. All procedures performed in studies involving human participants were in accordance with the ethical standards of the institutional research committee and with the 1964 Helsinki declaration and its later amendments or 
comparable ethical standards. The Wake Forest Health Sciences Institutional Review Board approved the study with a waiver of written informed consent.

\section{Study Eligibility and Data Collection}

Eligible survivors included those who were at least 21 years of age, diagnosed with nonmetastatic breast cancer, and at least 3 months after potentially curative cancer treatment (ie, surgery, chemotherapy, or radiation), excluding maintenance hormonal therapy. Additional inclusion criteria included no current evidence of disease or a history of cancer recurrence, a working email address, and ability to read medical information in English. Survivors were ineligible for the study if they had visual impairments that prohibited them from viewing material on a tablet device or if they were enrolled in hospice care or had a life expectancy less than 6 months. Survivors were identified through clinic appointment schedules and contacted by a research member prior to their appointment by telephone or immediately before their appointment in the waiting room.

Eligible providers included medical, radiation, gynecologic, and surgical oncologists; nurse practitioners, and physician assistants who provided survivorship care to posttreatment cancer survivors. A list of eligible oncologists, nurse practitioners, and physician assistants was procured from the oncology service line administrators, and providers were emailed an invitation to participate.

All participants provided informed consent prior to participation, and the study was approved by the Wake Forest Health Sciences Institutional Review Board (number 37786). Survivor participants completed a baseline survey, viewed the Vigor-Us tool (Figure 1) with their cardiovascular health information on a tablet computer with the study research coordinator, and then completed a brief postsurvey. The total research visit time was 15 to 20 minutes. Separate from the survivor assessment, provider participants were provided with a prototype of the enhanced AH-HA tool (Figure 1) on a tablet computer, introduced to the manipulation of slider bars and buttons, and asked to use the tool as they might with a cancer survivor. Providers also completed brief assessments before and after viewing the tool. Both survivor and provider participants received a US \$10 gift card.

\section{Cardiovascular Health Assessment Tools}

The AH-HA tool (Figure 1) visualizes data regarding the AHA Simple 7 modifiable cardiovascular heath factors-BMI, smoking status, blood pressure, total cholesterol level, hemoglobin $\mathrm{A}_{1 \mathrm{c}}$ or fasting glucose level, healthy diet, and physical activity [27] - to promote discussions at the point of care between breast cancer survivors and oncology providers. AH-HA was adapted from the SPHERE [30] primary care tool to include information about receipt of potentially cardiotoxic chemotherapies (ie, anthracyclines, antimetabolites, hormone therapy, aromatase inhibitors, monoclonal antibodies, antimicrotubule agents, alkylating agents, and radiation) [32] and was designed to be integrated with electronic health records (EHR) using Fast Healthcare Interoperability Resources [33]. Breast cancer survivors viewed a patient-facing version of the SPHERE tool designed for personal computers and mobile devices, the Vigor-Us app (Figure 1). This app did not contain information about receipt of potentially cardiotoxic chemotherapies because our clinical advisory group felt that this information was best discussed with a medical provider.

\section{Measures}

Survivor cardiovascular risk information abstracted from the medical record include weight, height, smoking status, blood pressure, total cholesterol level, and hemoglobin $\mathrm{A}_{1 \mathrm{c}}$ level; self-reported factors included smoking, physical activity, and diet (Table 1). Survivor knowledge of cardiovascular health and perceived importance and appropriateness of heart health discussions during oncology care were evaluated with 6 questions assessing confidence in understanding risk of heart disease, understanding steps needed to improve heart health, perception that cancer (or heart disease) poses a risk to health, and desire to talk to a provider (oncologist or primary care provider) about heart health. Survivors were also asked about the numerical value of each heart health factor (with "I don't know" as an option) and to rate each health factor as high (poor health), somewhat high (intermediate health), or low-risk (ideal health) according to Table 1. Following their use of the tool, survivors completed the same 6 preassessment questions along with 3 additional questions reflecting acceptability of heart health discussions with oncologists prior to, during, and after treatment completion. Survivor tool acceptability was assessed with 5 questions on a 5-point Likert scale (strongly agree to strongly disagree) regarding liking the tool, helpfulness, ease of understanding, picture/diagram improved understanding, and desire to use this tool with oncologist. Survivors also reported gender, race and ethnicity, years of education, internet and email usage, and health literacy [34].

Provider self-reported demographic and practice data included gender, race/ethnicity, years in practice, and percentage of time spent in patient care. Provider usability was assessed using 6 questions utilized in our previous study of general internal medicine physicians [29] assessing useful information, promotion of effectiveness, ease in accessing needed information, information meets needs, easy to use, and useful format. These questions were rated on a 7-point Likert scale from strongly agree to strongly disagree. Three questions reflecting potential use of tool prior to, during, and after treatment completion were rated on a 4-point Likert scale (never, almost, always, almost always).

\section{Statistical Analyses}

For this pilot study, the sample size for the oncology provider survey $(n=20)$ is driven primarily by feasibility concerns. For the survivor survey, we estimated power to test the hypothesis that responses to each Likert scale question are generally positive, which we defined as testing the alternative hypothesis that the mean score for each question is greater than 3.5 (where a score of 3 denotes a neutral response to the question). Assuming a sample of 50 survivors and a standard deviation of 1.0 , we will have $>80 \%$ power provided the true mean score for a particular question is 3.9 or greater (roughly corresponds to an average response of agree). 
We conducted descriptive analyses and summarized oncology provider and survivor demographics and survey responses with counts and percentages. Providers' responses were assessed on a 7-point Likert scale from strongly disagree to strongly agree; we categorized responses of 5-7 as agreeing. Survivors' responses were assessed on a 5-point Likert scale from strongly agree to strongly disagree; responses of agree or strongly agree were categorized as agreeing. Wilcoxon signed rank tests were used to compare breast cancer survivors' knowledge regarding their cardiovascular risk factors and perceived importance of cancer and heart disease before and after viewing the tool. Comparisons were made individually for each of the 6 questions included on the questionnaire about cardiovascular risk factor knowledge and perceived importance and appropriateness of heart health discussions during oncology care. Sidak correction for multiple testing were utilized due to the 6 questions; $P$ values $<.0085$ were considered significant for these outcomes. We calculated the percent of survivors who reported "I don't know" for each cardiovascular risk factor. Among those who did respond with a value for their risk factor, we calculated percent agreement between categorization of objective EHR data and the survivor's subjective assessment. Finally, we present survivor and provider data on usability of the tools. Specifically, we calculated the percent of survivors and providers who agreed or strongly agreed with the usability questions, and we presented data on the preferred timing of the intervention according to survivors and providers.

\section{Results}

Sociodemographic and Health Characteristics of Breast Cancer Survivors

We enrolled 49 breast cancer survivors (Table 2). An additional 13 survivors were screened and not enrolled (4 did not have an email address, 6 were not interested, and 3 could not stay after an appointment). The majority of enrolled survivors (92\%) had an early-stage cancer and were on 11 years postdiagnosis (mean 10.8 years, SD 6); all received surgical treatment, 55\% (27/49) received chemotherapy, and $69 \%$ (34/49) received radiation. With regards to receipt of potentially cardiotoxic cancer treatments, one-third $(17 / 49,35 \%)$ had received treatment with an anthracycline; almost half received hormone therapy (24/49, $49 \%) ; 45 \%$ (22/49) received aromatase inhibitors, 6\% (3/49) received monoclonal antibodies, 29\% (14/49) received antimicrotubule agents, $43 \%$ (21/49) received alkylating agents, and $8 \%(4 / 49)$ received antimetabolites. Almost half of survivors $(23 / 49,47 \%)$ reported graduating from college, and 96\% (47/49) reported adequate health literacy. Most had a cell phone (47/49, $96 \%)$, used the internet $(43 / 49,88 \%)$, and used email almost every day $(34 / 49,69 \%)$. Almost all, survivors $(47 / 49,96 \%)$ completed the postvisit assessment and provided cardiovascular health tool usability data. 
Table 2. Characteristics of breast cancer survivor $(n=49)$ and oncology provider $(n=20)$ participants for usability testing of the AH-HA tool.

\begin{tabular}{|c|c|c|}
\hline Characteristic & Breast cancer survivors $(n=49)$ & Oncology providers $(n=20)$ \\
\hline \multicolumn{3}{|l|}{ Age (years), n (\%) } \\
\hline$<65$ & $28(57)$ & $\mathrm{N} / \mathrm{A}^{\mathrm{a}}$ \\
\hline$\geq 65$ & $21(43)$ & N/A \\
\hline \multicolumn{3}{|l|}{ Sex, n $(\%)$} \\
\hline Female & $49(100)$ & $12(60)$ \\
\hline Male & $0(0)$ & $8(40)$ \\
\hline \multicolumn{3}{|l|}{ Race, $\mathbf{n}(\%)$} \\
\hline White & $41(84)$ & $14(70)$ \\
\hline Black or African American & $4(8)$ & $2(10)$ \\
\hline Asian & $1(2.0)$ & $1(5)$ \\
\hline Southeast Asian & $0(0)$ & $3(15)$ \\
\hline American Indian & $0(0)$ & $1(5)$ \\
\hline More than one race & $2(4)$ & $0(0)$ \\
\hline Unknown & $1(2)$ & $0(0)$ \\
\hline Hispanic ethnicity, n (\%) & $2(4)$ & $2(10)$ \\
\hline Time since cancer diagnosis (years), mean (SD) & $10.8(6.0)$ & N/A \\
\hline \multicolumn{3}{|l|}{ Cancer treatment received, $\mathrm{n}(\%)$} \\
\hline Surgery & $49(100)$ & N/A \\
\hline Chemotherapy & $27(55)$ & N/A \\
\hline Radiation & $34(69)$ & N/A \\
\hline \multicolumn{3}{|l|}{$\mathrm{AJCC}^{\mathbf{b}}$ stage, $\mathrm{n}(\%)$} \\
\hline 0 & $4(8)$ & N/A \\
\hline I & $23(47)$ & N/A \\
\hline II & $18(37)$ & N/A \\
\hline III & $4(8)$ & N/A \\
\hline \multicolumn{3}{|l|}{ Education level, n (\%) } \\
\hline$\leq$ High school & $7(14)$ & N/A \\
\hline Some college & $19(40)$ & N/A \\
\hline College graduate & $23(47)$ & N/A \\
\hline \multicolumn{3}{|l|}{ Email use every day or almost every day, n (\%) } \\
\hline Yes & $34(69)$ & N/A \\
\hline No & $15(31)$ & N/A \\
\hline \multicolumn{3}{|l|}{ Internet use past 30 days, $n(\%)$} \\
\hline Yes & $43(88)$ & N/A \\
\hline No & $6(12)$ & N/A \\
\hline \multicolumn{3}{|l|}{ Adequate health literacy, n (\%) } \\
\hline Yes & $47(96)$ & N/A \\
\hline No & $2(4)$ & N/A \\
\hline \multicolumn{3}{|l|}{ Provider type, n (\%) } \\
\hline Physician (MD or DO) & N/A & $14(70)$ \\
\hline Physician assistant/nurse practitioner & N/A & $6(30)$ \\
\hline
\end{tabular}




\begin{tabular}{lll}
\hline Characteristic & Breast cancer survivors $(\mathrm{n}=49)$ & Oncology providers $(\mathrm{n}=20)$ \\
\hline Years in practice, $\mathbf{n}(\boldsymbol{\%})$ & $\mathrm{N} / \mathrm{A}$ & $8(40)$ \\
$\leq 5$ & $\mathrm{~N} / \mathrm{A}$ & $4(20)$ \\
$6-10$ & $\mathrm{~N} / \mathrm{A}$ & $8(40)$ \\
$\geq 11$ & & \\
Oncology specialty, $\mathbf{n}(\boldsymbol{\%})$ & N/A & $13(65)$ \\
$\quad$ Hematology & N/A & $1(5)$ \\
Radiation & N/A & $6(30)$ \\
Surgical & \multicolumn{2}{|c}{} \\
Time spent in direct patient care, $\mathbf{n}(\boldsymbol{\%})$ & N/A & $4(20)$ \\
$\leq 50 \%$ & N/A & $7(35)$ \\
$51-75 \%$ & N/A & $9(45)$ \\
$>75 \%$ & &
\end{tabular}

${ }^{\mathrm{a}} \mathrm{N} / \mathrm{A}$ : not applicable.

${ }^{\mathrm{b}}$ AJCC: American Joint Committee on Cancer.

\section{Cardiovascular Health and Awareness of Breast Cancer Survivors}

Prior to viewing the tool, $90 \%$ of survivors (44/49) agreed that cancer posed a risk to their health, and 84\% (41/49) agreed that cardiovascular disease posed a risk to their health. On average, only $45 \%$ (range $0 \%-86 \%$ ) of survivors' known cardiovascular health factors were reported to be at an ideal level. More than $50 \%$ of survivors reported smoking status $(45 / 49,92 \%)$ and blood pressure $(26 / 49,53 \%)$ in the ideal category; less than one-third reported BMI, diet, and physical activity in the ideal range (Figure 2). 
Figure 2. Proportion of breast cancer survivors $(\mathrm{n}=49$ ) reporting poor (red), intermediate (yellow), ideal (green), and missing (gray) cardiovascular health factors. CVH: cardiovascular health.

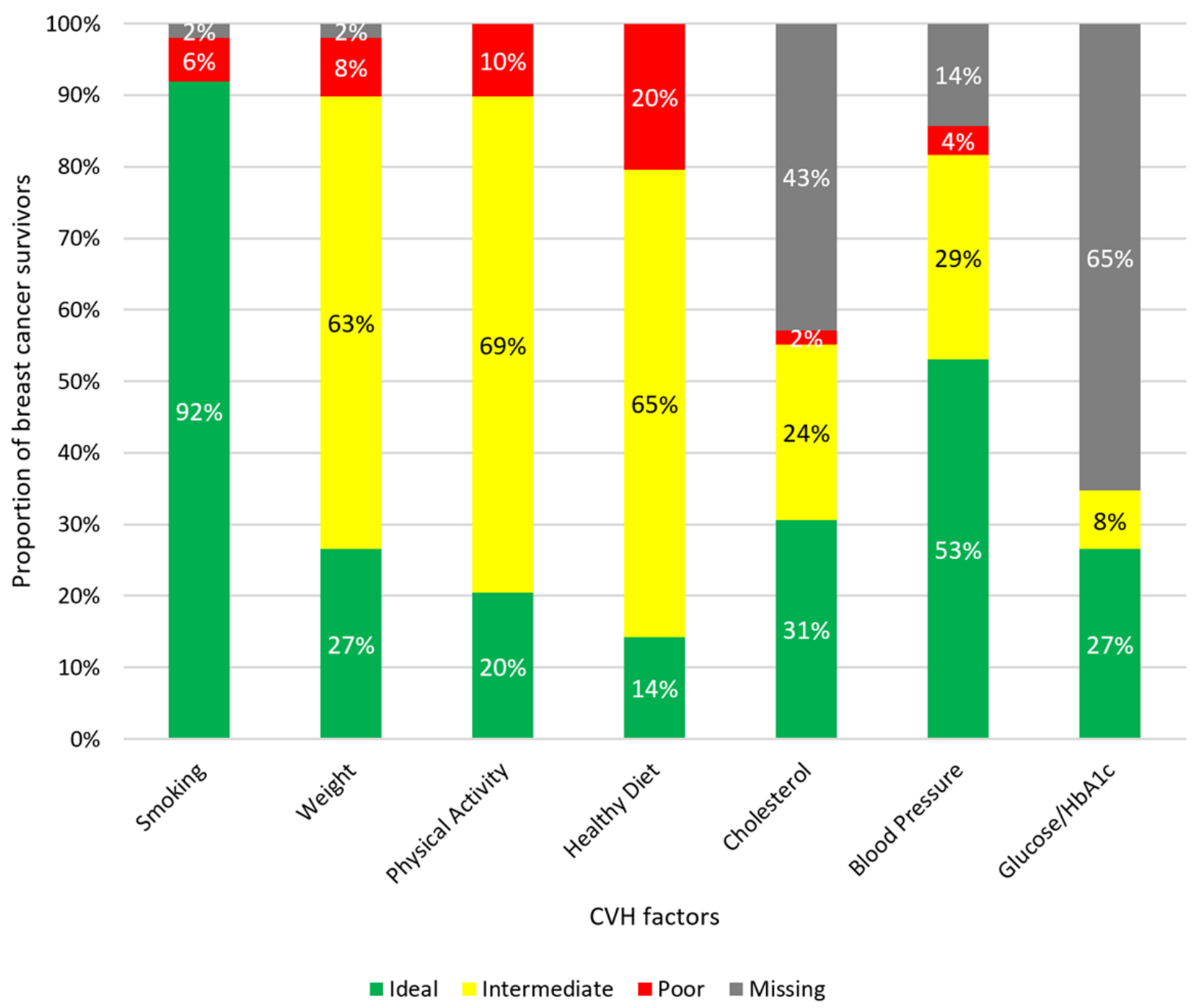

Prior to viewing the tool, $24 \%$ of survivors (12/49) expressed strong agreement that they understood their risk of cardiovascular disease; 58\% (28/49) agreed. Yet 65\% (32/49) reported not knowing the level for one or more cardiovascular health factors (range 0-4). Cardiovascular risk factors most likely to be self-reported as "not known" (Figure 2) included hemoglobin $\mathrm{A}_{1 \mathrm{c}}(44 / 49,90 \%)$, blood glucose level (32/49, 65\%), cholesterol level $(21 / 49,43 \%)$, blood pressure $(7 / 49,14 \%)$, and
BMI $(1 / 49,2 \%)$. When comparing concordance between the EHR and self-report for categorization of cardiovascular health factors as ideal vs nonideal among survivors who knew the categorization of their factor, $90 \%$ of survivors (44/49) were concordant for BMI, $47 \%$ (23/49) were concordant for blood pressure, 28\% (14/49) were concordant for blood glucose level, and $34 \%(17 / 49)$ were concordant for cholesterol level (Figure $3)$. 
Figure 3. Survivor characterization of cardiovascular health factors. CVH: cardiovascular health; EHR: electronic health record.

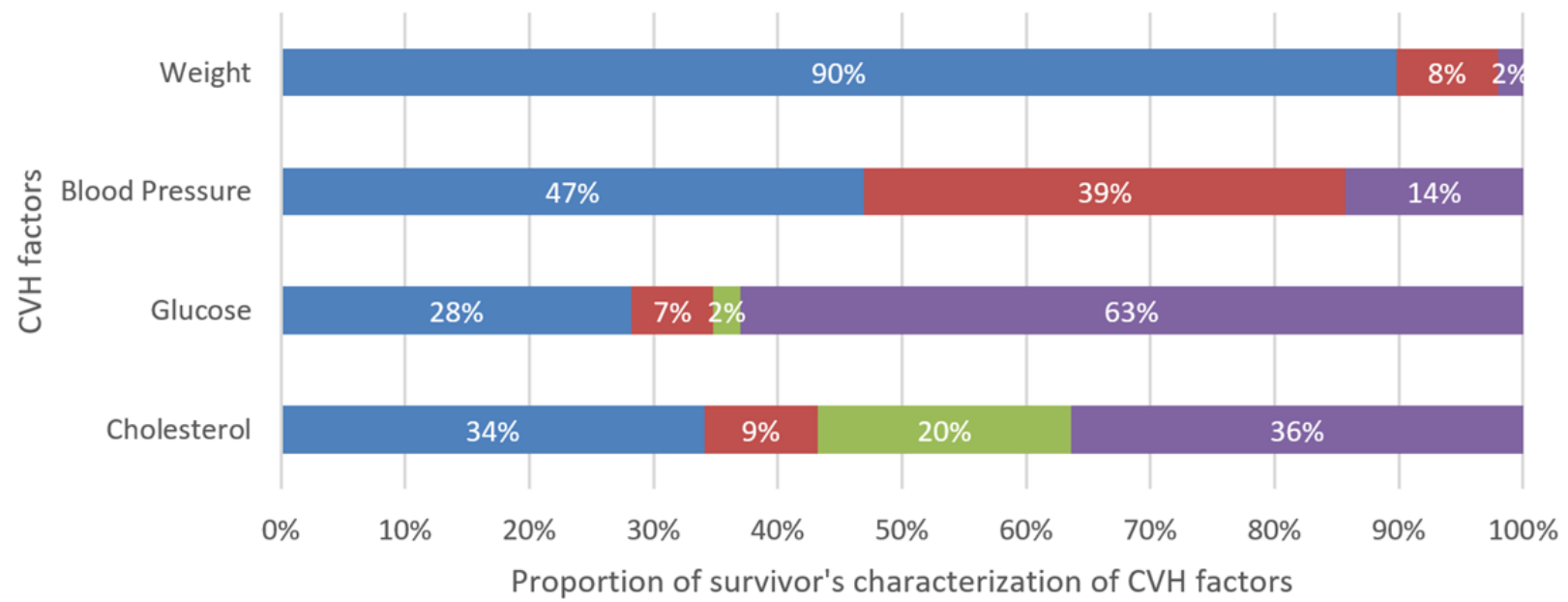

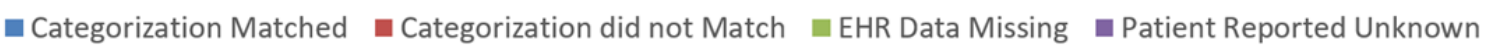

\section{Usability of the Tool Among Breast Cancer Survivors}

Usability ratings of the tool by breast cancer survivors are shown in Figure 4. The majority of breast cancer survivors thought the tool was easy to understand $(48 / 49,98 \%)$, improved their understanding $(45 / 49,92 \%)$, and was helpful $(45 / 49,92 \%)$;
94\% (46/49) liked the tool and agreed oncologists should discuss heart health during survivorship care. A majority $(34 / 49,69 \%)$ would like to use the tool with their oncologist at a future appointment. There were no differences in usability statistics by those 65 years and older versus those younger than 65 years.

Figure 4. Usability ratings of the tools among breast cancer survivors and oncology providers. CVH: cardiovascular health.

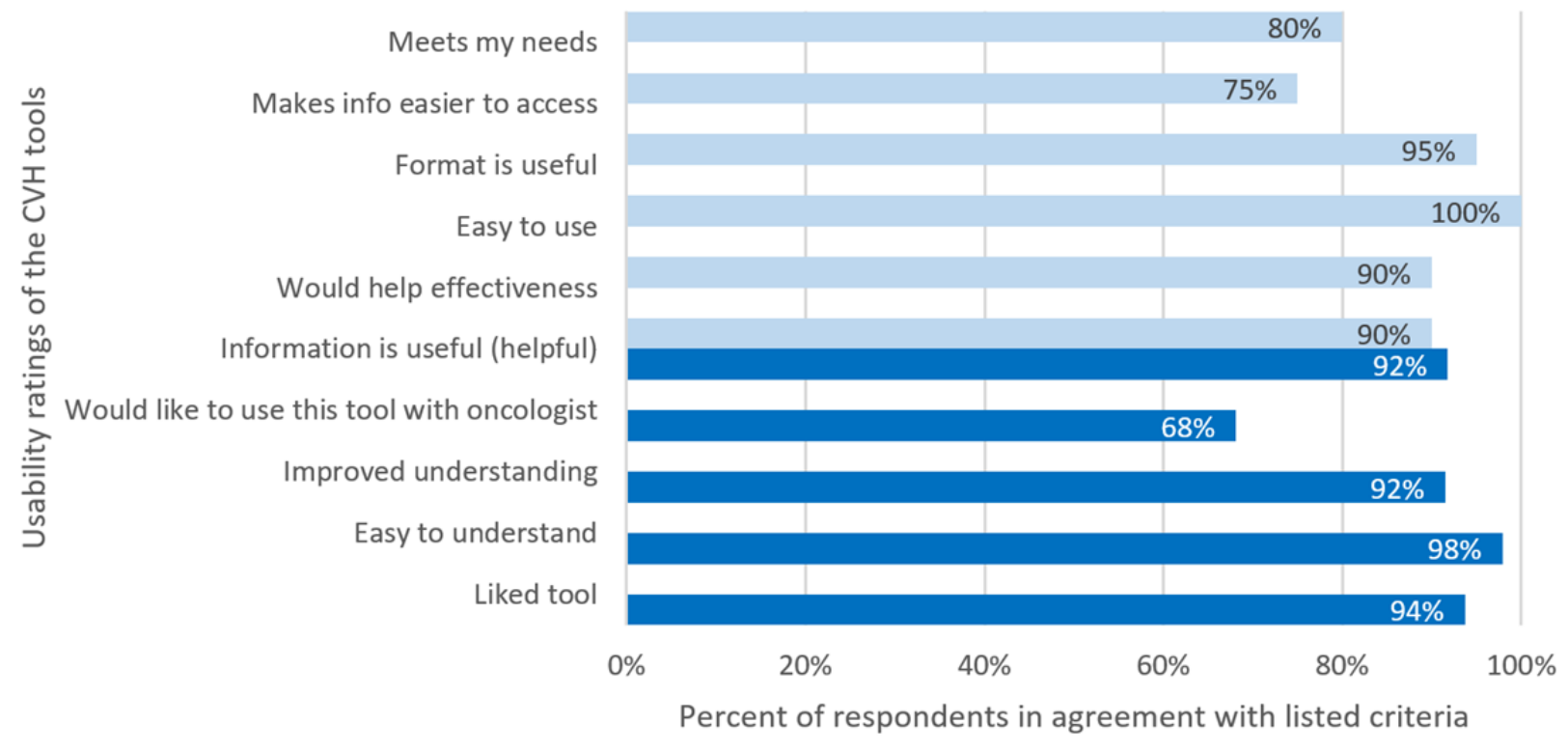

Providers $(\mathrm{N}=20)$

We also assessed survivors' perception of cardiovascular risk before and after viewing the tool (Figure 5). For all variables, survivors reported that they were in stronger agreement with the statements after viewing the tool (Figure 5). Significant changes were observed for understanding of cardiovascular risk ( $S=-65, P=.009)$, understanding steps to improve cardiovascular health $(S=-70.5, P<.001$, perception of health risk from cardiovascular disease $(S=-45, P=.007)$, and desire to discuss cardiovascular risk with a primary care provider $(S=-121$, $P<.001)$. There was no significant change in perception of health risk from cancer or desire to discuss cardiovascular risk with an oncologist. 
Figure 5. Proportion of breast cancer survivors $(n=47)$ whose cardiovascular health perceptions changed before and after viewing the assessment tool.

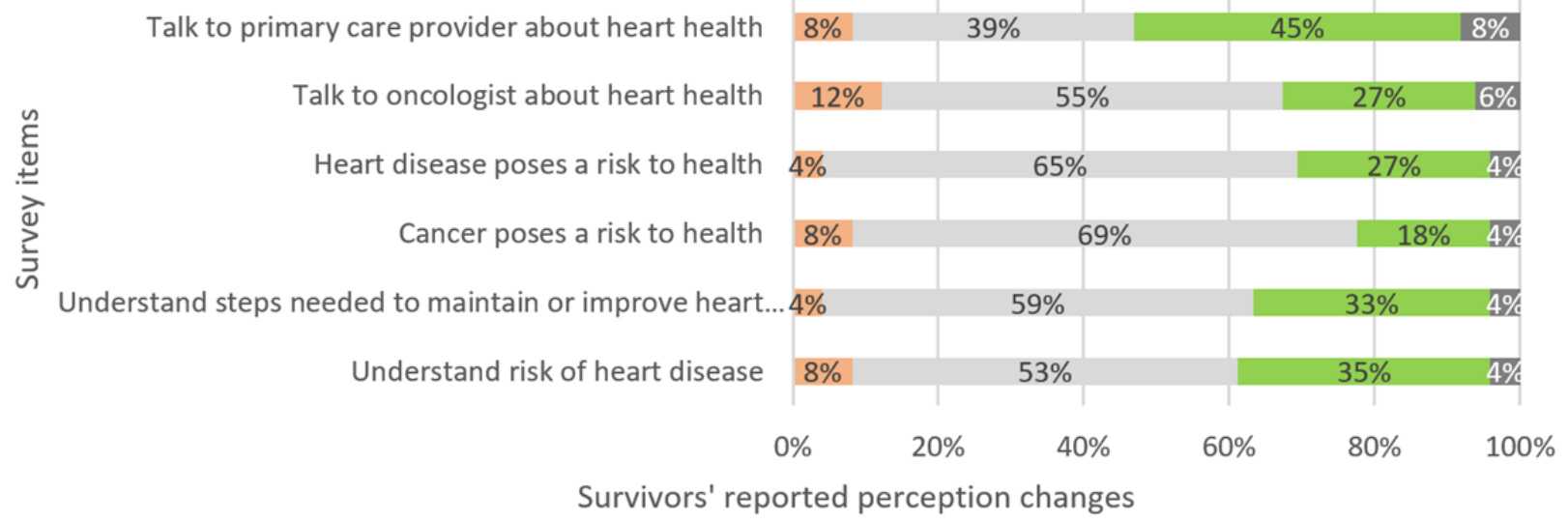

More Strongly NOT in Agreement $\square$ No Change $\quad$ More Strongly in Agreement $\square$ Missing Data

\section{Sociodemographic and Practice Characteristics of Providers}

We enrolled 14 physicians, 2 physician assistants, and 4 nurse practitioners; $60 \%(12 / 20)$ were female, $70 \%$ (14/20) were White, $10 \%(2 / 20)$ were Black, and $10 \%(2 / 20)$ identified as Hispanic or Latino (Table 2). Hematology oncology was defined as the practice specialty for $65 \%$ of providers (13/20), $60 \%$ $(12 / 20)$ had been practicing as an attending for more than 5 years, and $80 \%(16 / 20)$ spent more than $50 \%$ of their time in direct patient care. Only 50\% (10/20) reported usually or always talking to their posttreatment patients about cardiovascular health, and 35\% (7/20) usually or always initiated discussion about cardiovascular health with posttreatment patients. However, 95\% (19/20) reported it was somewhat or very important to discuss cardiovascular health with posttreatment patients. About half of providers $(9 / 20,45 \%)$ reported a high level of comfort with cardiovascular health discussions.

\section{Usability of the Tool Among Oncology Providers}

Usability ratings of the tool by providers are shown in Figure 4. Most providers agreed the tool provided useful information $(18 / 20,90 \%)$, would help their effectiveness $(18 / 20,90 \%)$, was easy to use $(20 / 20,100 \%)$, and presented information in a useful format (19/20, 95\%); and 85\% of providers (17/20) reported they would use the tool most or all of the time when providing survivorship care, with $50 \%(10 / 20)$ reporting the same for initial treatment planning and $45 \%$ (9/20) during active treatment.

\section{Discussion}

\section{Principal Results}

Overall, our results suggest both the need for and suitability of a tailored cardiovascular health assessment tool to heighten awareness of cardiovascular health among oncology providers and breast cancer survivors. We present the first usability data from breast cancer survivors and oncology providers on the usability of EHR-integrated cardiovascular health assessment tools. On average, only $45 \%$ of breast cancer survivors' known cardiovascular health factors were at an ideal level, most survivors did not know the value or categorization of at least one of their cardiovascular health factors, and $94 \%$ of survivors (46/49) thought oncologists should discuss heart health during survivorship care. Nearly all providers indicated that it was either somewhat important or very important to discuss cardiovascular health with posttreatment patients. However, less than half of providers reported a high level of comfort with cardiovascular health discussions, and only half reported usually or always talking to their posttreatment patients about cardiovascular health. Usability data from providers and survivors demonstrate positive perceptions of the cardiovascular health apps; $85 \%$ of providers (17/20) reported they would use the tool most or all of the time when providing survivorship care. Thus, we conclude that clinical decision support tools such as AH-HA have potential to provide relevant data to providers at the point of care to initiate discussions and prompt appropriate referrals to primary care and cardiology-settings in which cardiovascular health can be managed effectively.

The use of the AH-HA and Vigor-Us tools are one strategy for improving risk assessment and personalized cardiovascular disease prevention in cancer survivorship programs, a research priority identified by the AHA [2]. A majority of breast cancer survivors did not know one or more of their cardiovascular health risk factors, despite a majority expressing agreement before viewing the tool that they understood their risk of heart disease. In particular, knowledge gaps exist among survivors with respect to their hemoglobin $\mathrm{A}_{1 \mathrm{c}}$ and cholesterol values, which are strong independent predictors of cardiovascular disease [35]. Self-reported understanding of cardiovascular risk increased among survivors with use of the tool, and survivors increased their interest in discussing their heart health with primary care providers following the use of the tool. This increased awareness and interest may facilitate linking survivors back into primary care so these risks can be addressed.

\section{Comparison With Prior Work}

Our results are consistent with our previous evaluation of general cardiovascular health clinical decision support in the primary care setting. In our previous study [29], providers indicated that the content and the accuracy of the tool met their needs always 
or most of the time. Primary care providers felt the tool was clear and presented data in a useful format, was easy to use and user-friendly, and provided up-to-date information in a timely manner [29].

\section{Limitations}

Limitations of this study include the smaller sample size, nonrandomized usability assessment, single-institution setting, and the absence of data regarding the impact of the tool on cardiovascular health and health care utilization. Although we focused on breast cancer survivors in this usability study, the tool may also be appropriate for other survivor populations who have significant competing risk from cardiovascular disease. Future testing of this tool should take place in more diverse multi-institutional settings.

\section{Conclusions}

The AH-HA point-of-care EHR-based visualization tool brings together personalized cardiovascular health and contextual cancer treatment data to address potential gaps in breast cancer survivorship care. Our previous SPHERE study [29] suggested that cardiovascular health clinical decision support tools are well-received in the primary care setting. Findings from the current study suggest that oncology providers and breast cancer survivors would benefit from and value the integration of cardiovascular health clinical decision support apps in survivorship care. A newly initiated study will test the effectiveness and implementation of the AH-HA app in a clinic-randomized trial in community oncology practices.

\section{Acknowledgments}

This project was supported by the National Center for Advancing Translational Sciences, National Institutes of Health (grant award number UL1TR001420) and the Wake Forest Baptist Comprehensive Cancer Center Biostatistics Shared Resource, supported by the National Cancer Institute's Cancer Center Support (grant award number P30CA012197). This project was a pilot to our current National Institutes of Health and National Cancer Institute funded study (grant award number 1R01CA226078-01). The content is solely the responsibility of the authors and does not necessarily represent the official views of the National Institutes of Health.

\section{Conflicts of Interest}

None declared.

\section{References}

1. Shelburne N, Adhikari B, Brell J, Davis M, Desvigne-Nickens P, Freedman A, et al. Cancer treatment-related cardiotoxicity: current state of knowledge and future research priorities. J Natl Cancer Inst 2014 Sep;106(9) [FREE Full text] [doi: 10.1093/jnci/dju232] [Medline: 25210198]

2. Mehta LS, Watson KE, Barac A, Beckie TM, Bittner V, Cruz-Flores S, American Heart Association Cardiovascular Disease in WomenSpecial Populations Committee of the Council on Clinical Cardiology; Council on CardiovascularStroke Nursing;Council on Quality of CareOutcomes Research. Cardiovascular disease and breast cancer: where these entities intersect: a scientific statement from the American Heart Association. Circulation 2018 Feb 20;137(8):e30-e66 [FREE Full text] [doi: 10.1161/CIR.0000000000000556] [Medline: 29437116]

3. Hanrahan EO, Gonzalez-Angulo AM, Giordano SH, Rouzier R, Broglio KR, Hortobagyi GN, et al. Overall survival and cause-specific mortality of patients with stage T1a,bN0M0 breast carcinoma. JCO 2007 Nov 01;25(31):4952-4960. [doi: 10.1200/jco.2006.08.0499]

4. Chapman JW, Meng D, Shepherd L, Parulekar W, Ingle JN, Muss HB, et al. Competing causes of death from a randomized trial of extended adjuvant endocrine therapy for breast cancer. J Natl Cancer Inst 2008 Feb 20;100(4):252-260 [FREE Full text] [doi: 10.1093/jnci/djn014] [Medline: 18270335]

5. Bradshaw PT, Stevens J, Khankari N, Teitelbaum SL, Neugut AI, Gammon MD. Cardiovascular disease mortality among breast cancer survivors. Epidemiology 2016 Jan;27(1):6-13 [FREE Full text] [doi: 10.1097/EDE.0000000000000394] [Medline: 26414938]

6. Jones LW, Haykowsky MJ, Swartz JJ, Douglas PS, Mackey JR. Early breast cancer therapy and cardiovascular injury. J Am Coll Cardiol 2007 Oct 09;50(15):1435-1441 [FREE Full text] [doi: 10.1016/j.jacc.2007.06.037] [Medline: 17919562]

7. Armenian SH, Xu L, Ky B, Sun C, Farol LT, Pal SK, et al. Cardiovascular disease among survivors of adult-onset cancer: a community-based retrospective cohort study. J Clin Oncol 2016 Apr 01;34(10):1122-1130 [FREE Full text] [doi: 10.1200/JCO.2015.64.0409] [Medline: 26834065]

8. Dent SF, Kikuchi R, Kondapalli L, Ismail-Khan R, Brezden-Masley C, Barac A, et al. Optimizing cardiovascular health in patients with cancer: a practical review of risk assessment, monitoring, and prevention of cancer treatment-related cardiovascular toxicity. Am Soc Clin Oncol Educ Book 2020 Mar;40:1-15 [FREE Full text] [doi: 10.1200/EDBK 286019] [Medline: 32213102]

9. Lenihan DJ, Cardinale DM. Late cardiac effects of cancer treatment. J Clin Oncol 2012 Oct 20;30(30):3657-3664. [doi: 10.1200/JCO.2012.45.2938] [Medline: 23008297]

10. Cardinale D, Bacchiani G, Beggiato M, Colombo A, Cipolla CM. Strategies to prevent and treat cardiovascular risk in cancer patients. Semin Oncol 2013 Apr;40(2):186-198. [doi: 10.1053/j.seminoncol.2013.01.008] [Medline: 23540744] 
11. Weaver KE, Foraker RE, Alfano CM, Rowland JH, Arora NK, Bellizzi KM, et al. Cardiovascular risk factors among long-term survivors of breast, prostate, colorectal, and gynecologic cancers: a gap in survivorship care? J Cancer Surviv 2013 Jun;7(2):253-261 [FREE Full text] [doi: 10.1007/s11764-013-0267-9] [Medline: 23417882]

12. Vincent L, Leedy D, Masri SC, Cheng RK. Cardiovascular disease and cancer: is there increasing overlap? Curr Oncol Rep 2019 Apr 06;21(6):47. [doi: 10.1007/s11912-019-0796-0] [Medline: 30955114]

13. Institute of Medicine, National Research Council, Hewitt M, Greenfield S, Stovall E. From cancer patient to cancer survivor: lost in transition. In: The National Academies Press. Washington, DC: The National Academies Press; 2005.

14. Institute of Medicine. Cancer survivorship care planning 2005. American Psychosocial Oncology Society. Washington, DC: The National Academies Press; 2005 Nov. URL: https://apos-society.org/wp-content/uploads/2016/06/ factsheetcareplanning.pdf [accessed 2020-03-16]

15. Institute of Medicine, Levit LA, Balogh EP, Nass SJ, Ganz PA. Delivering high-quality cancer care: charting a new course for a system in crisis. In: The National Academies Press. Washington, DC: The National Academies Press; 2013.

16. Ammon M, Arenja N, Leibundgut G, Buechel RR, Kuster GM, Kaufmann BA, et al. Cardiovascular management of cancer patients with chemotherapy-associated left ventricular systolic dysfunction in real-world clinical practice. J Card Fail 2013 Sep;19(9):629-634. [doi: 10.1016/j.cardfail.2013.07.007] [Medline: 24054339]

17. Stump TK, Robinson JK, Yanez B, Penedo F, Ezeofor A, Kircher S, et al. Physicians' perspectives on medication adherence and health promotion among cancer survivors. Cancer 2019 Dec 01;125(23):4319-4328 [FREE Full text] [doi: 10.1002/cncr.32410] [Medline: 31448414]

18. Kelley M, Foraker R, Lin ED, Kulkarni M, Lustberg M, Weaver KE. Oncologists' perceptions of a digital tool to improve cancer survivors' cardiovascular health. ACI Open 2019 Oct 03;03(02):e78-e87. [doi: 10.1055/s-0039-1696732]

19. Weaver KE, Aziz NM, Arora NK, Forsythe LP, Hamilton AS, Oakley-Girvan I, et al. Follow-up care experiences and perceived quality of care among long-term survivors of breast, prostate, colorectal, and gynecologic cancers. J Oncol Pract 2014 Jul;10(4):e231-e239 [FREE Full text] [doi: 10.1200/JOP.2013.001175] [Medline: 24695901]

20. Emery JD, Shaw K, Williams B, Mazza D, Fallon-Ferguson J, Varlow M, et al. The role of primary care in early detection and follow-up of cancer. Nat Rev Clin Oncol 2014 Jan;11(1):38-48. [doi: 10.1038/nrclinonc.2013.212] [Medline: 24247164]

21. Rasmussen-Torvik LJ, Shay CM, Abramson JG, Friedrich CA, Nettleton JA, Prizment AE, et al. Ideal cardiovascular health is inversely associated with incident cancer: the Atherosclerosis Risk In Communities study. Circulation 2013 Mar 26;127(12):1270-1275 [FREE Full text] [doi: 10.1161/CIRCULATIONAHA.112.001183] [Medline: 23509058]

22. Davies NJ, Batehup L, Thomas R. The role of diet and physical activity in breast, colorectal, and prostate cancer survivorship: a review of the literature. Br J Cancer 2011 Nov 8;105 Suppl 1:S52-S73 [FREE Full text] [doi: 10.1038/bjc.2011.423] [Medline: 22048034]

23. Cespedes Feliciano EM, Kwan ML, Kushi LH, Weltzien EK, Castillo AL, Caan BJ. Adiposity, post-diagnosis weight change, and risk of cardiovascular events among early-stage breast cancer survivors. Breast Cancer Res Treat 2017 Apr;162(3):549-557 [FREE Full text] [doi: 10.1007/s10549-017-4133-8] [Medline: 28176174]

24. Thomson CA, Rock CL, Thompson PA, Caan BJ, Cussler E, Flatt SW, et al. Vegetable intake is associated with reduced breast cancer recurrence in tamoxifen users: a secondary analysis from the Women's Healthy Eating and Living Study. Breast Cancer Res Treat 2011 Jan;125(2):519-527. [doi: 10.1007/s10549-010-1014-9] [Medline: 20607600]

25. Caan BJ, Kwan ML, Shu XO, Pierce JP, Patterson RE, Nechuta SJ, et al. Weight change and survival after breast cancer in the after breast cancer pooling project. Cancer Epidemiol Biomarkers Prev 2012 Aug;21(8):1260-1271 [FREE Full text] [doi: 10.1158/1055-9965.EPI-12-0306] [Medline: 22695738]

26. Lahart IM, Metsios GS, Nevill AM, Carmichael AR. Physical activity, risk of death and recurrence in breast cancer survivors: A systematic review and meta-analysis of epidemiological studies. Acta Oncol 2015 May;54(5):635-654. [doi: 10.3109/0284186X.2014.998275] [Medline: 25752971]

27. Lloyd-Jones DM, Hong Y, Labarthe D, Mozaffarian D, Appel LJ, Van HL, et al. Defining and setting national goals for cardiovascular health promotion and disease reduction: the American Heart Association's strategic Impact Goal through 2020 and beyond. Circulation 2010 Feb 2;121(4):586-613 [FREE Full text] [doi: 10.1161/CIRCULATIONAHA.109.192703] [Medline: 20089546]

28. Payne PRO, Lussier Y, Foraker RE, Embi PJ. Rethinking the role and impact of health information technology: informatics as an interventional discipline. BMC Med Inform Decis Mak 2016 Mar 29;16:40 [FREE Full text] [doi: 10.1186/s12911-016-0278-3] [Medline: 27025583]

29. Foraker RE, Kite B, Kelley MM, Lai AM, Roth C, Lopetegui MA, et al. EHR-based visualization tool: adoption rates, satisfaction, and patient outcomes. EGEMS (Wash DC) 2015;3(2):1159 [FREE Full text] [doi: 10.13063/2327-9214.1159] [Medline: 26290891]

30. Foraker RE, Shoben AB, Lopetegui MA, Lai AM, Payne PRO, Kelley M, et al. Assessment of Life's Simple 7 in the primary care setting: the Stroke Prevention in Healthcare Delivery EnviRonmEnts (SPHERE) study. Contemp Clin Trials 2014 Jul;38(2):182-189. [doi: 10.1016/j.cct.2014.03.007] [Medline: 24721482]

31. Foraker RE, Shoben AB, Kelley MM, Lai AM, Lopetegui MA, Jackson RD, et al. Electronic health record-based assessment of cardiovascular health: The stroke prevention in healthcare delivery environments (SPHERE) study. Prev Med Rep 2016 Dec;4:303-308 [FREE Full text] [doi: 10.1016/j.pmedr.2016.07.006] [Medline: 27486559] 
32. Valachis A, Nilsson C. Cardiac risk in the treatment of breast cancer: assessment and management. Breast Cancer (Dove Med Press) 2015;7:21-35 [FREE Full text] [doi: 10.2147/BCTT.S47227] [Medline: 25653554]

33. Mandel JC, Kreda DA, Mandl KD, Kohane IS, Ramoni RB. SMART on FHIR: a standards-based, interoperable apps platform for electronic health records. J Am Med Inform Assoc 2016 Feb 17;23(5):899-908 [FREE Full text] [doi: 10.1093/jamia/ocv189] [Medline: 26911829]

34. Chew LD, Griffin JM, Partin MR, Noorbaloochi S, Grill JP, Snyder A, et al. Validation of screening questions for limited health literacy in a large VA outpatient population. J Gen Intern Med 2008 May;23(5):561-566 [FREE Full text] [doi: 10.1007/s11606-008-0520-5] [Medline: 18335281$]$

35. Dawber TR, Kagan A, Revotskie N, Stokes J. Factors of risk in the development of coronary heart disease--six year follow-up experience. the Framingham study. Ann Intern Med 1961 Jul;55:33-50. [doi: 10.7326/0003-4819-55-1-33] [Medline: $\underline{13751193]}$

\title{
Abbreviations
}

AHA: American Heart Association

AH-HA: Automated Heart-Health Assessment

EHR: electronic health record

SPHERE: Stroke Prevention in Healthcare Delivery Environments

\author{
Edited by G Eysenbach; submitted 09.04.20; peer-reviewed by D López López, H Chavan; comments to author 16.07.20; revised \\ version received 30.11.20; accepted 12.12.20; published 21.01.21 \\ Please cite as: \\ Weaver KE, Klepin HD, Wells BJ, Dressler EV, Winkfield KM, Lamar ZS, Avery TP, Pajewski NM, Hundley WG, Johnson A, Davidson \\ EC, Lopetegui $M$, Foraker RE \\ Cardiovascular Assessment Tool for Breast Cancer Survivors and Oncology Providers: Usability Study \\ JMIR Cancer 2021;7(1):e18396 \\ URL: http://cancer.jmir.org/2021/1/e18396/ \\ doi: $\underline{10.2196 / 18396}$ \\ PMID: 33475511
}

CKathryn E Weaver, Heidi D Klepin, Brian J Wells, Emily V Dressler, Karen M Winkfield, Zanetta S Lamar, Tiffany P Avery, Nicholas M Pajewski, W Gregory Hundley, Aimee Johnson, Eleanor C Davidson, Marcelo Lopetegui, Randi E Foraker. Originally published in JMIR Cancer (http://cancer.jmir.org), 21.01.2021. This is an open-access article distributed under the terms of the Creative Commons Attribution License (https://creativecommons.org/licenses/by/4.0/), which permits unrestricted use, distribution, and reproduction in any medium, provided the original work, first published in JMIR Cancer, is properly cited. The complete bibliographic information, a link to the original publication on http://cancer.jmir.org/, as well as this copyright and license information must be included. 